\title{
Strategi Pemasaran Pariwisata Sembalun Kecamatan Sembalun Kabupaten Lombok Timur Nusa Tenggara Barat
}

Sinta Virgilenna a, 1, I Putu Anom a, 2

${ }^{1}$ sivirgi@gmail.com, 2 putuanom@unud.ac.id

a Program Studi S1 Destinasi Pariwisata, Fakultas Pariwisata,Universitas Udayana, Jl. Dr. R. Goris, Denpasar, Bali 80232 Indonesia

\begin{abstract}
The number of tourist arrivals during the low season tends to decline. It also has an impact on sightseeing. Therefore, marketing strategy is very important to be able to increase the number of tourist visit to be able to compete with other tourism object and can give positive impact for society Sembalun. Sembalun tourism is located on Jalan Wisata Rinjani, Sembalun Bumbung, Kab. East Lombok Kec. Sembalun, Sembalun Village of West Nusa Tenggara. This study aims to determine the marketing mix, and marketing strategy at Sembalun Tour.

The data collection in this research is done by observation, in-depth interview, document and literature study. The determination of informants was determined on the basis of random purposive sampling in which subjects were chosen on the basis of specified criteria. These criteria are Sembalun tourism managers and communities around Sembalun East Lombok.

The result of this research is marketing mix at Sembalun tourism based on product, price, distribution channel, promotion, person, physical proof and process. In this research also discuss about SWOT analysis about the strengths, weaknesses, opportunities and threats that are owned by Sembalun tourism which is related to mix mix (marketing mix), from marketing strategy that is Increase promotion to other market, Increase cooperation with Travel agent good Outside and inside the country, improve access, improve the quality of human resources.
\end{abstract}

Keyword : Management, Marketing Mix, Marketing Strategy, Sightseeing Tour

\section{PENDAHULUAN}

Indonesia memiliki keindahan alam yang begitu indah, dari Sabang sampai Merauke dan keanekaragaman ilmiah. Hal ini juga ditambah dengan ragam budaya yang begitu banyak, dengan tradisi lokal yang pastinya tidak ditemukan didestinasi manapun. Keindahan alam dan budaya inilah yang indonesia memiliki yang membedakan dengan negara yang lain. Dengan keragaman kekayaan alam dan budaya inilah diharapkan pemerintah mampu melakukan pemasaran pariwisata.

Keanekaragaman wisata dan budaya di Indonesia memiliki ciri khas tersendiri serta keindahan alam yang berbeda, mulai dari tempat wisata dan objek wisata yang kaya akan keindahannya. Terdapat banyak ragam destinasi wisata Indonesia salah satunya Lombok Nusa Tenggara Barat yang menjadi favorit wisatawan mancanegara dan wisatawan lokal untuk belibur. Berlibur ke Lombok tidak lengkap rasanya jika tidak menikmati suasana pedesaan yang indah akan kebudayaan serta alamnya. Salah sataunya terletak di Wisata Sembalun, Kabupaten Lombok Timur. Wisata Sembalun ini terletak pada lereng gunung Rinjani. Dikenal sebagai destinasi wisata yang memiliki suasana pegunungan serta pemandangan sawah yang asri. Kelebihan dari
Wisata Sembalun ini yaitu memiliki curah iklim yang berbeda dengan destinasi pegunungan lainnya sehingga dapat menjadi keunggulanuntuk menarik minat wisatwan untuk berkunjung.

Tujuan dari adanya penelitian ini untuk memfokuskan strategi dan program pemasaran yang tepat dan efektif serta memperkenalkan kebuadayaan Indonesia pada pasar Internasional. Dikarenakan Sembalun memiliki Daya Tarik Wisata unggulan yang memiliki berbagai keunikan dan berbagai potensi wisata alam yang mendukung. Sehingga dapat memberikan masukan pada pihak pemerimtah maupun pengelola pada pemasaran yang akan mendatang.

\section{II.TINJAUAN PUSTAKA}

\subsection{Telaah Hasil penelitian sebelumnya}

Penelitian yang dilakukan Jenny Joehastanti (2012) berjudul "Strategi pemasaran wisata alam untuk meningkatkan kunjungan Wisatawan di kawasan wisara di Kabupaten Kediri" Penelitian ini memiliki kesamaan karena menggunkan teori yang sama yaitu marketing mix dan analisis SWOT.

\subsection{Kajian Konsep}

Penelitian ini menggunakan beberapa konsep yaitu: 
1. Strategi Pemasaran

Strategi pemasaran untuk menetapkan pasar dengan menetapkan posisi bauran pemasaran dan besarannya bauran pemasaran. Bauran pemasaran menurut Kotler dan Keller (2012) bauran pemasaran merupakan alat yang digunakan oleh perusahaan untuk menjual produknya kepada konsumen. Bauran pemasaran yaitu terdiri dari product, price, place, and promotion, people,physical evidence,process.

2. Pemasaran Pariwisata Pemasaran pariwisata yang diungkapkan oleh Krippedorf (dalam Yoeti,2002:1) kebijakan yang dilakukan perusahaan yang bergerak pada bidang kepariwisataan dalam usaha swasta atau pemerintah lokal, regional, nasional dan internasional untuk mencapai kepuasan optimal atas kebutuhan-kebutuhan wisatwan. Sekaligus untuk mencapai keuntungan yang wajar

\section{Konsep Daya Tarik Wisata}

Menurut Undang-undang Republik Indonesia Nomor 10 Tahun 2009, daya tarik wisata merupakan segala sesuatu yang mempunyai keunikan, kemudahan, dan nilai yang berwujud keanakaragaman, kekayaan alam, budaya, dan hasil buatan manusia yang menjadi sasaran atau kunjungan para wisatawan.

\section{III.METODE PENELITIAN}

Penelitian Wisata Sembalun ini terletak di Jalan Wisata Gunung Rinjani, Sembalun Bumbung Kabupaten Lombok Timur Kecamatan Sembalun, Desa Sembalun Nusa Tengga Barat yang memiliki luas wilayah sekitar 217,08 Km2. Ruang Lingkup penelitian sebagai yaitu kondisi Eksisting wisata Sembalun Kabupaten Lombok Timur Nusa Tenggara Barat dengan melakukan observasi dan menggunakan konsep daya tarik wisata dan Strategi Pemasaran wisata Sembalun Kabupaten Lombok Timur Nusa Tenggara Barat dengan menggunakan konsep Marketing Mix dan dimasukan kedalam analisis SWOT.

Pada penelitian ini yang termasuk data kualitatif adalah gambaran umum lokasi penelitian, potensi wisata sembalun, atraksi wisata sembalun dan strategi pemasaran di wisata Sembalun ini. Dan data kuantitif yang dimaksud berupa data-data statistik mengenai jarak/ luas Sembalun, jumlah kunjungan wisata, jumlah amenitas/ fasilitas, dan daya tarik yang terdapat di wisata Sembalun Lombok. Data primer dalam penelitian ini diperoleh dari hasil observasi sehingga mengetahui bagaimana lokasi penelitian, wawancara dengan informan di Sembalun serta kondisi eksistingnya dapat mengetahui perkembangan yang sedang berlangsung di Sembalun, dan mengetahui stategi pemasaran pada wisata Sembalun. Data sekunder diperoleh dari dokumen tentang monografi di Sembalun. Dan data tertulis seperti dokumen pribadi atau resmi yang terdiri dari jumlah kunjungan wisata,data mengenai jarak/luas di Sembalun, dan jumlah amenitas/fasilitas.

Penelitian ini menggunakan teknik pengumpulan data yaitu: observasi, wawancara, dan studi dokumen (Sugiyono, 2014). Untuk menentukan informan menggunakan teknik purpoive sampling, yaitu peneliti mengetahui orang-orang yang akan dijadikan informan yaitu pengelola Wisata Sembalun dan Masyarakat disekitar Sembalun. Teknik analisis data dalam penelitian ini menggunakan analisis SWOT.

\section{HASIL DAN PEMBAHASAN}

Wisata Sembalun terletak di Desa Sembalun Nusa Tengga Barat berketinggian 800 mdpl-1.250 mdpl. Desa Sembalun ini berkembang menjadi agrowisata yang mengundang wisatawan lokal dan mancanegara untuk menikmati panorama alam dan udara segar pegunungan. Jika ditempuh dari Bandara International Lombok Praya yang terletak di Lombok Tengah dapat ditempuh sekitar kurang lebih 2 jam Untuk menuju lokasi. Menuju Sembalun dapat melewati dua jalur yaitu jalur timur atau utara.

Wisata Sembalun merupakan desa wisata yang berbasis alam dan agrowisata. Wilayah ini memiliki iklim cuaca yang unik yang tidak dimiliki oleh destinasi wisata lainnya. Karena Suhu di musim kemarau, suhu normal mencapai 7 derajat celsius-12 derajat celsius, sedangkan di musim hujan sekitar 20 derajat celsius inilah yang membedakan sembalun dengan destinasi wisata lainnya. Tidak hanya terkenal dengan gunung rinjaninya saja wisata sembalun ini juga memiliki pemandangan (view) pegunungan serta persawahan yang hijau diiringi dengan udara yang dingin. Wisata sembalun memiliki aktivitas wisata yang cukup banyak diantranya 
terdapat hikking gunung rinjani, wisata petik stroberry, Air terjun dan tak kalah juga ada taman wisata pusuk sembalun lokasinya berada diatas sehingga dapat menikmati pemandangan tebing-tebing curam yang indah secara langsung serta pemdangan yang hijau dari atas taman pusuk sembalun.

Fasilitas-fasilitas disekitar sembalun juga lengkap karena adanya Hotel atau Home Stay, Restauran Mini market semua usaha pariwisata ini murni milik masyarakat Sembalun dan juga dikelola oleh masyarakat sekitar sembalun. Terdapat pula fasilitas pendukung lainnya seperti Sport foto, fasilitas ini cocok untuk anak muda jaman sekarang yang suka (selfie) untuk mengabadikan momen.

\subsection{Daya Tarik Wisata Sembalun}

Adanya daya tarik wisata di Sembalun ini dapat menjadikan sasaran wisata untuk mengunjungui suatu objek wisata yang ada di Sembalun. Berikut objek wisata dan daya tarik wisata Sembalun :

1. Daya tarik wisata Alam pada Wisata Sembalun: Gunung Rinjani, Air Terjun Mangku Sakti, Air Terjun Mangku Kodek dan kebun strawberry.

2. Daya Tarik Budaya Pada Wisata Sembalun: Rumah Adat Sembahulun, seni budaya Tari Tradisional (Tandang Mendet, Cupak Gurontang dan Wayang Wong).

3. Daya tarik wisata hasil karya manusia pada Wisata Sembalun: Kain tenun khas Sembalun, Taman Wisata Pusuk Sembalun,Home Stay/ Hotel Sport Foto.

\subsection{Bauran Pemasaran Pada Wisata Sembalun.}

Pemasaran yang dibahas dalam penelitian ini adalah keseluruhan dari kegitan usaha yang ditunjukan untuk merencanakan produk,harga, promosi, saluran distribusi, personal,bukti fisik dan proses untuk memuaskan konsumen yaitu sebagai berikut :

1. Produk (produk) yang dimaksud disini adalah produk yang dimiliki oleh wisata Sembalun yang akan dijual kepada para wisatawan dengan harapan produk yang dimiliki akan disukai oleh para wisatawan yang datang untuk mengunjungi objek wisata tersebut.
Adapaun produk yang di tawarkan yaitu: Trekking Rinjani, Air Terjun Mangku Sakti, Wisata Petik Stawberry, Air Terjun Mangku Kodek, Taman Wisata Pusuk Sembalun Hotel / Home Stay.

2. Harga (price) yang dimaksud disini adalah nilai yang diterapkan oleh pengelola wisata Sembalun. Harga yang ditetapkan oleh wisata Sembalun dengan menggunakan mata uang rupiah (Rp) untuk semua wisatawan baik wisatawan nusantara maupun mancanegara. Adapun tarif-tarif yang ditetapkan oleh pengelola wisata sembalun adalah sebagai berikut: Traking Rinjani: Nusantara (Wisatawan Lokal) :Rp. 7.500.00,-/Per Hari (weekend). RP. 5.000,00,-/Per Hari (weekday). Mancanegara (Wisatawan Asing) : Rp. 150.000.00,- / Per Trip . Asuransi: Rp. 10.000,00,- /Per Orang. Tiket Masuk Wisata Petik Stroberry: Rp. 10.000.00,- / per orang. Memetik dan membeli Stroberry:Rp. 50.000.00,-/ Kg. Homestay/Hotel: Hari Biasa Kisaran:Rp.300.000,00,sampai Rp. 600.000.00,- / Hari. Hari Libur Kisaran: Rp. 700. 000,00,sampai Rp.1.000.000.00,-/ Hari.

3. Saluran Distribusi (Place) pada wisata Sembalun yaitu Pemasaran langsung: Wisatawan $\rightarrow$ Objek Wisata Sembalun. Sistem pemasaran secara langsung ini dimana wisatawan sebagai konsumen langsung datang tanpa melalui perantara. Tetapi jika menggunakan pemasaran Tidak Langsung yaitu: Wisatawan $\rightarrow$ Travel Agent atau Hotel $\rightarrow$ Wisata Sembalun. Pada sistem distribusi ini wisatawan datang ke melalui perantara pihak terkait.

4. Kegiatan promosi (Promotion) yang dilakukan oleh pihak pengelola wisata Sembalun yaitu dengan berbagai media seperti periklanan mengunakan media cetak atau 
media sosial. Serta mengunakan personal selling Personal selling ini dilakukan agar calon wisatawan dapat secara langsung mendatangi wisata di sembalun untuk mendapatkan informasi yang lengkap. Dan melakukan promosi penjualan Promosi penjualan ini dapat dilakukan dengan cara memberikan discount kepada wisatawan. Dan memberikan komisi pada penjalin kerjasama.

5. Personel (people) dalam wisata sembalun ini melibatakan warga sekitar sembalun dalam upaya pelayanan dan kepuasaan wisatawan. Sehingga yang memegang kunci keberhasilan kepuasaan pengunjung adalah masyarakat sembalun dan pengelola wisata sembalun.

6. Proses (Procces) yang dapat dilakukan untuk menuju wisata Sembalun. (1) Wisatawan melakukan reservasi terlebih dahulu melalui travel agent atau Home stay, sopir ataupun wisatawan yang datang langsung mengujungi ke wisata Sembalun. (2) Wisatawan yang sudah melakukan resevasi atau melalui travel agent dapat langsung menuju home stay yang dipesan dan dapat melakukan aktivitas wisatanya dengan di dampingi guide. Akan tetapi jika wisatawan tidak melakukan reservasi atau langsung datang ketempat juga dapat memesan home stay sendiri sesuai keinginan atau hanya untuk sekedar berkunjung dan menikmati aktivitas wisata saja. (3) Selanjutnya wisatawan bebas melalakukan aktivitas wisata yang diinginkan, seperti melakukan Treakking rinjani, wisata memetik stroberry, mengunjungi air terjun, mengunjungi pantai ataupun hanya sekedar menikmati keindahan alamnya atau berfoto-foto (selfie) disekitar wisata Sembalun
7. Bentuk fisik (Physical Evidence) dari wisata sembalun ini adalah produk yang berbentuk Treakking rinjani, wisata petik strawberry, wisata pantai, wisata air terjun, restauran, mini market, dan struktur bangunan- bangunan Rumah adar khas Lombok yang ada di Sembalum, serta sport foto disekitar wisata sembalun dan fasilitasfasilitas lain yang dimiliki wisata sembalun sehingga cukup mendukung untuk dapat memberikan kepuasan kepada para pengunjung

\subsection{Pendekatan SWOT}

Analisis SWOT ini untuk mencari kekuatan, kelemahan, peluang serta ancaman.

1. (Strenghts) Kekuatan yang dimiliki wisata Sembalun (1)Wisata Sembalun Memiliki pemandangan alam (view) yang masih alami karena disekelilingnya terdapat sawah-sawah yang hijau serta pemandangan indah pegunungan dan udara yang sejuk. (2) Berlibur wisata sembalun tidak semua produk wisatanya memerlukan biaya yang mahal hanya untuk parkir saja. (3) Sembalun memiliki ciri khas budaya sasak yang masih kental hingga saat ini. (4)Wisata Sembalun juga dinobatkan sebagai wisata Halal. (5)Sembalun memiliki keunikan iklim tersendiri.

2. (Weaknesses) Kelemahan pada wisata Sembalun (1) Kurangnya Fasilitasfasilitas umum lainnya belum menunjang seperti toilet umum dan kurangnya mesin ATM. (2)Akses menuju wisata sembalun cukup susah dijangkau. (3) Sararana pendukung yang ada masih tidur atau belum aktif seperti cafe dan restauran yang tidak beroprasi dengan baik. (4) Kurangnya promosi dari pihak pengelola seperti promosu melalui browsur dll.

3. (Opportunities) Peluang (1) Gunung Rinjani dikenal wisatawan sebagai gunung vulkanik yang masih aktif nomor 2 tertinggi di Indonesia. (2) Wisata Sembalun berpeluang 
dikembangkan karena didukung oleh lingkungan alam yang bagus serta dikelilingi oleh pemandangan (view) sawah yang hijau dan pemandangan pegunungan. (3) Ekonomi masyarakat sekitar sembalun meningkat.

4. (Threats) Ancaman pada wisata Sembalun (1) Kurangnya kerjasama dengan travel agent maupun perusahaan pariwisata lainnya. (2) Sumber Daya Manusia cenderung tidak memiliki latar belakang pariwisata. (3) Menurunnya jumlah kunjungan wisata ke wisata sembalun. (4) Akan ditinggalakan karena kurangnya penataan objek yang kurang optimal. (5) Adanya persaingan objek wisata lainnya dengan suasana yang sama

5. Hasil dari penelitian ini dikaji menggunakan strategi SO,ST,WO dan WT adalah sebagai berikut: (1) strategi $S O$ yaitu Meningkatkan promosi kepada pasar yang lain dengan memanfaatkan media seperti internet dan browsur (2) strategi $S T$ yaitu Mengadakan kerjasama dengan Travel agent dan perusahaan pariwisata baik diluar maupun di dalam negeri untuk mengatasi adanya persaingan (3) Strategi $W O$ yaitu Memperbaikan akses jalan dan memberikan tanda adanya objek wisata Sembalun Sehingga akses wisatawan dapat lebih mudah untuk menuju wisata Sembalun. (4) strategi WT yaitu Meningkatkan kualitas Sumber Daya Manusia untuk masyarakat dan pengelola sehingga prefesional di bidang pariwisata untuk menghindari ketidak nyamanan wisatawan saat melakukan aktivitas wisata.

\section{SIMPULAN DAN SARAN}

\subsection{Simpulan}

1. Kondisi Eksisting Wisata Sembalun: Wisata Sembalun memiliki wisata daya tarik Alam: Gunung Rinjani, Air Terjun Mangku Sakti, Air Terjun Mangku Kodek kebun strawberry. Daya tarik buatan yaitu: Rumah Adat Sembahulun, seni budaya Tari Tradisional (Tandang Mendet, Cupak Gurontang dan Wayang
Wong), Serta memiliki Daya tarik buatan yaitu berupa : Kain Tenun Khas Sasak, Taman Wisata Pusuk Sembalun,Home Stay/ Hotel Sport Foto.

2. Strategi pemasaran yang dapat diterapkan pada objek wisata Sembalun adalah: (1) strategi SO yaitu Meningkatkan promosi kepada pasar yang lain dengan memanfaatkan media seperti internet dan browsur (2) strategi $S T$ yaitu Mengadakan kerjasama dengan Travel agent dan perusahaan pariwisata baik diluar maupun di dalam negeri untuk mengatasi adanya persaingan (3) Strategi $W O$ yaitu Memperbaikan akses jalan dan memberikan tanda adanya objek wisata Sembalun Sehingga akses wisatawan dapat lebih mudah untuk menuju wisata Sembalun. (4) strategi WT yaitu Meningkatkan kualitas Sumber Daya Manusia untuk masyarakat dan pengelola sehingga prefesional di bidang pariwisata untuk menghindari ketidak nyamanan wisatawan saat melakukan aktivitas wisata

\subsection{Saran}

1. Memperbaiki akses jalan menuju Air Terjun agar mudah untuk dikunjungi wisatawan. Perlu Menambahkan fasilitas- fasilitas yang kurang seperti : toilet umum, Toko oleh-oleh, mesin ATM dll. Kepada masyarakat lokal sebaiknya dapat menciptakan produk baru yang lebih mencerminkan keaslian budaya sasak, karena hal ini yang akan menjadi daya tarik tersendiri bagi wisatawan untuk berkunjung.

2. Menjaga dan meningkatkan kerja sama dengan travel agent, hotel dan semua pihak terkait. Meningkatkan SDM masyarakat dengan cara meningkatkan pendidikan dan melakukan pelatihan terhadap masyarakat setempat, terutama pengelola wisata Sembalun dan usaha wisata Sembalun harus terus ditingkatkan seperti sikap ramah tamah, sopan satun dan keamanan, agar wisatawan merasa nyaman saat berwisata. Promosi perlu dioptimalkan khususnya pada web side (internet) yang dimiliki wisata sembalun dan mempromosikan menggunakan berbagi 
media lainnya seperti media elektronik dan media cetak seperti (televisi/ radio dan browsur wisata Sembalun).

\section{DAFTAR PUSTAKA}

Republik Indonesia. 2009. Undang Undang Republik Indonesia No.10 Tahun 2009 Tentang Kepariwisataan. Jakarta Sekretariat Negara

Joehastanti, Jenney. 2012 "Strategi Pemasaran Wisata Alam Untuk Meningkatkan Kunjungan Wisatawan Di Kawasan Wisata Di Kabupaten Kediri." Laporan Akhir. Kediri

Kotler, Philip. 2004. Manajemen Pemasaran. Edisi Millenium. Jakarta: PT Prenhallindo.

Kotler, Philip dan Kelvin L. Keller. 2012.

Marketing Mangement :14 Edition. New Jersey: Pretince Hall

Kotler, Philip dan Gary Amstrong. 2012 . Prinsipprinsip Pemasaran. Edisi 13. Jilid 1. Jakarta: Erlangga.

Sugiyono, 2014. Metode Penelitian Pendidikan (Pendekatan Kualitatif dan Kuantitatif dan R\&D). Bandung. Alfabeta

Yoeti,A ,Oka, .2002 Pemasaran Pariwisata, Jakarta: Angkasa
3. Perlu diadakan penelitian lanjutan dengan waktu yang cukup panjang guna memperdalam penelitian. 